immunised; age 2-6 years) and the high incidence rate of infection among the non-immunised group cast doubt on the validity of the comparison group. An uncontrolled trial with 14 valent vaccine over two years ${ }^{11}$ reported an incidence rate for pneumococcal sepsis of $4 \cdot 4 / 100$ patient years compared with incidence rates in historical comparison groups of $5 \cdot 8,{ }^{2}$ and $9 \cdot 0^{11}$ in children under 5 . These very high incidence rates compared with those noted in this study suggest either that pneumococcal disease is much more common in North America or, more likely, that serious election biases influenced the patients joining such studies.

Our data suggest that pneumococcal vaccine given in the mode and at the ages detailed does not protect against pneumococcal infection. The use of booster doses or adjuvants may improve antibody response and clinical efficacy, but experimental confirmation is needed. In the mean time penicillin offers the most effective prophylaxis and must continue beyond the age of 3 years. Pneumococcal vaccine should be given as late as possible during the period of penicillin coverage.

The pneumococcal and $H$ influenzae $\mathrm{B}$ vaccines were donated by Merck, Sharpe, and Dohme under the NIAID collaborative pneumococcal vaccine study programme, coordinated by Dr James C Hill, of the National Institutes of Health. Mr Richard Peto provided valuable advice on study design.

\section{References}

${ }^{1}$ Barrett-Connor E. Bacterial infection and sickle cell anemia. Medicine $1971 ; 50: 97-112$

${ }^{2}$ Overturf GD, Powars D, Baraff LJ. Bacterial meningitis and septicaemia in sickle cell disease. Am $\mathcal{F}$ Dis Child 1977;131:784-7.

${ }^{3}$ Rogers DW, Vaidya S, Serjeant GR. Early splenomegaly in homozygous sickle cell disease: an indicator of susceptibility to infection. Lancet 1978;ii:963-5.
' Landesman SH, Rao SP, Ahonkhai VI. Infections in children with sickle cell anemia. Special reference to pneumococcal and salmonella infections. Am $\mathcal{F}$ Pediatr Hematol Oncol 1982;4:407-15.

5 Hansman D, Devitt L, Miles H, Riley I. Pneumococci relatively insensitive to penicillin in Australia and New Guinea. Med F Aust 1974;ii:353-6.

${ }^{6}$ Tempest B, Carney JP, Eberle B. Distribution of the sensititivities to penicillin of types of Diplococcus pneumoniae in an American Indian population. F Infect Dis $1974 ; 130: 67-9$.

: Appelbaum PC, Bhamjee A, Scragg JN, Hallett AF, Bowen AJ, Cooper RC. Streptococcus pneumoniae resistant to penicillin and chloramphenicol. Lancet 1977; ii:995-7.

* Ginsberg CM, McCracken GH, Zweighaft TC. Serum penicillin concentrations after intramuscular administration of benzathine penicillin $\mathrm{G}$ in children. Pediatrics $1982 ; 69: 452-4$.

${ }^{9}$ Ahonkhai VI, Landesman SH, Fikrig SM, et al. Failure of pneumococcal vaccine in children with sickle-cell disease. $N$ Engl f Med 1979;301: 26-7.

${ }^{10}$ Broome CV, Facklam RR, Fraser DW. Pneumococcal disease after pneumococcal vaccination. An alternative method to estimate the efficacy of pneumococcal vaccine. $N$ Engl f Med 1980;303:549-52.

11 Overturf GD, Rigau-Perez JG, Honig G, et al. Pneumococcal polysaccharide immunization of children with sickle cell disease. II. Serologic response and pneumococcal disease following immunization. $A m \mathcal{F}$ Pediatr Hematol Oncol 1982;4:25-35.

12 Borgono JM, McLean AA, Vella PP, et al. Vaccination and revaccination with polyvalent pneumococcal polysaccharide vaccines in adults and infants. Proc Soc Exp Biol Med 1978;157:148-54.

13 Cowan MJ, Ammann AJ, Wara DJ, et al. Pneumococcal polysaccharide immunization in infants and children. Pediatrics 1978;62:721-7.

14 Weibel RE, Vella PP, McLean AA, Woodhour Af, Davidson WL, Hilleman MR. Studies in human subjects of polyvalent pneumococcal vaccines. Proc Soc Exp Biol Med 1977;156:144-50.

${ }^{15}$ Ammann AJ, Addiego J, Wara DW, Lubin B, Smith WB, Mentzer WC. Polyvalent pneumococcal-polysaccharide immunization of patients with sickle-cell anemia and patients with splenectomy. $N$ Engl f Med $1977 ; 297: 897-900$.

16 Buchanan GR, Schiffman G. Antibody responses to polyvalent pneumococcal vaccine in infants with sickle cell anemia. 7 Pediatr $1980 ; 96: 264-6$

(Accepted 22 March 1984)

\title{
Pelvic infection: a comparison of the Dalkon shield and three other intrauterine devices
}

\author{
R SNOWDEN, B PEARSON
}

\begin{abstract}
A detailed analysis was undertaken of reports of possible pelvic infection in relation to the use of four commonly fitted intrauterine contraceptive devices during 1971 to 1978 in the United Kingdom. The four devices were the Dalkon shield, Lippes loops 3C and 2D, and the Gravigard (copper 7), and data used were those collected systematically through the UK intrauterine device research network. Prospective reports that the Dalkon shield was uniquely related to high levels of infection when compared with other intrauterine devices were not substantiated in this prospective study among 13349 users. Though some factors such as social class and previous experience of abortion appeared to influence the rate of infection, the type of intrauterine
\end{abstract}

University of Exeter, Exeter EX4 6DT

R SNOWDEN, PHD, director, Institute of Population Studies

B PEARSON, MSC, lecturer in economic and social statistics

Correspondence to: Dr R Snowden. device being worn did not appear to be a significant factor. Various methods of analysis were used including life table, regression, and discriminant analysis, using information relating to the type of intrauterine device worn, the characteristics of the user, the fitting centre, and the pattern of diagnosis and treatment of reported or suspected pelvic infection.

The results of this study suggest that fears that the Dalkon shield may be associated with a higher incidence of pelvic infection than other intrauterine devices may have been unjustified.

\section{Introduction}

For almost a decade the Dalkon shield intrauterine device has been the subject of inquiry about its relation to pelvic infection, which has sometimes caused infertility, septic spontaneous abortion, and even death. Some reports have condemned the Dalkon shield ${ }^{1}$ while others have claimed that the Dalkon shield is itself the victim of unjustified claims. ${ }^{2}$ One major problem has been the absence of prospective data among a sufficient number of women wearing this intrauterine device. 
Most published reports are based on a small number of women with a defined condition whose antecedent history has then been retrospectively assessed. There are two problems associated with this approach: firstly, a lack of "satisfied" Dalkon shield users to act as a comparison group and, secondly, a hostile climate of opinion during the time when the retrospective data were collected. Adverse publicity is likely to influence both the reporting of events that took place sometimes years earlier and the selective interpretation of such events based on information which received little attention at the time but which has since become of interest.

Difficulty in diagnosing pelvic inflammatory disease is well known, and the removal of bias in collecting and interpreting information relating to it needs special care. What is needed is a set of prospective data relating to a cohort of Dalkon shield users collected at a time and in such a way that hindsight cannot directly create undue bias. Ideally, this information should be of a comparative nature. The United Kingdom intrauterine device research network has such information.

The network consists of a number of clinics in various parts of England and a clinic in each of Scotland and Wales. The research activities of the network are coordinated by the Institute of Population Studies, University of Exeter. The network evolved as the need for systematically collected data relating to the use of intrauterine devices became apparent during the 1960 s, but it was not until 1971 that the network became firmly established with each clinic using similar data collection procedures and follow up administration within a framework of agreed event definitions, centralised data processing, statistical analysis, and report writing. The information collected currently constitutes the largest data set on the use of intrauterine devices in the United Kingdom. From 1971 to mid-1978 each of the cooperating clinics forwarded to Exeter all information relating to intrauterine devices obtained at the clinic irrespective of the device, type of information, or the conduct of a specific trial which may have been taking place. Since 1978 the network has continued to operate but has confined its activities to testing of new devices and procedures as the need has arisen.

One advantage of collecting data on all intrauterine devices from these clinics between 1971 and 1978 was that information was being systematically recorded about devices not under trial and about events considered unimportant or of little relevance at the time. Some, but not all, of the information was stored by computer, and the remainder was kept on the forms sent by the clinics. Despite some destruction of information-for example, as a result of a specific request by the staff at one clinic-most of the information is still available.

\section{Methods}

Because of the renewed interest in the relation between infection and the use of intrauterine devices resulting from the Dalkon shield inquiries in the mid-1970s we decided to re-examine all the forms relating to the four most popular devices being fitted in the United Kingdom between January 1971 and December 1975. These dates were selected because the Dalkon shield was introduced into the United Kingdom in 1971 and withdrawn in 1975. The devices selected were the two largest sizes of Lippes loop (3C and 2D), the Gravigard (copper 7), and the Dalkon shield. We concentrated on fittings during this period with follow up of these fittings extending to March 1978. Just under 90000 individual forms were re-examined and any reference to infection was carefully noted and subsequently assessed.

The data on all four devices were collected prospectively. Each completed follow up form succeeded in order from the date of fitting, and these forms were sent to the coordination centre each month. This information therefore related to women who experienced infection and those who did not on a prospective basis. By including the four most popular devices fitted in the United Kingdom during the same time period we were able to make comparisons among different intrauterine devices. These data were also collected at a time when those caring for the users of intrauterine devices were unaware of the concern later expressed about the Dalkon shield. To make a comparison between the selected devices we decided to confine the analysis of data to those clinics where the Dalkon shield was being fitted routinely and where at least one of the other three devices was also being fitted over the period studied. The removal of single device clinics reduced (but did not entirely eliminate) the intrusion of clinic factors affecting the reporting rate of infection. It should be borne in mind that these data were collected from the general experience of the clinics and not as part of a randomised trial. We hoped that by using the same clinic staff, the same recording procedures, and the same follow up administration, data processing, and analysis during the same period of time undue bias would be removed.

Initially all fitting and follow up records relating to the four devices at each of these clinics were examined, but we subsequently limited analysis to parous women when we found that the Dalkon shield was severely underrepresented and the Gravigard overrepresented among nulliparous women. The Dalkon shield was not routinely fitted among nulliparous women in the United Kingdom. Infection rates may differ when comparing nulliparous and parous women and to avoid the non-comparability of data this refinement of the sample was undertaken. As a further refinement we later restricted the analysis to the first known fitting (see below) since women wearing the Gravigard were more often routinely refitted with the device than those fitted with the other three devices.

\section{Results}

Each report of infection was examined to determine whether or not the intrauterine device had been removed during treatment and where such removal or treatment took place. The months of observation from the date of fitting to the occurrence of the reported event were also recorded together with information relating to the clinic and user. The rates for each of the events were computed for the four devices using established life table techniques. ${ }^{3}$

Table I indicates that there was no significant difference between the four devices when compared with each other over the same period of use and whether or not the treatment for suspected infection led to removal of the intrauterine device. The rate of suspected infection for all four devices was less than two cases among every 100 women during each year the device was worn. None of the four devices studied provided significantly higher or lower rates than the other three. What is more, the rate of infection appeared to be relatively constant over time and did not rise the longer the intrauterine device was worn. (The rates given in tables I and II are, of course, cumulative rates.)

Table I includes all cases where the examining doctor indicated infection by marking the appropriate box on the follow up form together with those cases where the doctor noted a complaint of pain and on examination observed tenderness and swelling of the adnexae. Infection was recorded if these observations were followed by a prescription for antibiotics of some kind even if the pelvic infection box on the form had not been specifically marked. Doctors often record infection in terms of its symptoms on the follow up formpain, bleeding, tenderness, etc-rather than make a firm diagnosis of pelvic infection.

To avoid the possibility of bias in interpretation we also analysed

TABLE I-Gross cumulative rates of infection reported per 100 women. Values in parentheses are $95 \%$ confidence limits

\begin{tabular}{|c|c|c|c|c|c|}
\hline Case & $\begin{array}{l}\text { Months } \\
\text { of use }\end{array}$ & $\begin{array}{l}\text { Lippes } \\
\text { loop 2D }\end{array}$ & $\begin{array}{l}\text { Lippes } \\
\text { loop 3C }\end{array}$ & Gravigard & $\begin{array}{c}\text { Dalkon } \\
\text { shield }\end{array}$ \\
\hline Device removed & $\begin{array}{l}12 \\
24 \\
36 \\
48 \\
60\end{array}$ & $\begin{array}{l}0.3(0.1-0.6) \\
0.7(0.3-1.3) \\
1.0(0.4-1.7) \\
1.4(0.6-2 \cdot 2) \\
2.5(1.2-3.9)\end{array}$ & $\begin{array}{l}0.6(0 \cdot 3-0.9) \\
1.0(0.5-1 \cdot 4) \\
1.2(0 \cdot 7-1 \cdot 8) \\
1.5(0.9-2 \cdot 1) \\
2.9(1 \cdot 8-4 \cdot 1)\end{array}$ & $\begin{array}{l}0.5(0 \cdot 2-0 \cdot 7) \\
1.4(0.9-2 \cdot 0) \\
2.6(1 \cdot 8-3 \cdot 4) \\
2.6(1 \cdot 8-3 \cdot 4)\end{array}$ & $\begin{array}{l}0.6(0 \cdot 3-0 \cdot 8) \\
1.2(0 \cdot 8-1 \cdot 7) \\
1.9(1 \cdot 3-2 \cdot 5) \\
2 \cdot 1(1 \cdot 5-2 \cdot 8) \\
2.8(1.9-3 \cdot 6)\end{array}$ \\
\hline Device not removed & $\begin{array}{l}12 \\
24 \\
36 \\
48 \\
60\end{array}$ & $\begin{array}{l}0.5(0.2-1 \cdot 0) \\
1.1(0.5-1 \cdot 7) \\
1.5(0.7-2 \cdot 3) \\
2.6(1.4-3 \cdot 8) \\
2.6(1.4-3 \cdot 8)\end{array}$ & $\begin{array}{l}0.4(0 \cdot 2-0 \cdot 7) \\
0.7(0 \cdot 3-1 \cdot 0) \\
1.0(0 \cdot 5-1 \cdot 1) \\
1.2(0 \cdot 6-1 \cdot 8) \\
2.0(1 \cdot 1-2 \cdot 9)\end{array}$ & $\begin{array}{l}0.8(0.5-1 \cdot 1) \\
1.4(0.9-1.8) \\
1.9(1.3-2 \cdot 5) \\
1.9(1.3-2 \cdot 5)\end{array}$ & $\begin{array}{l}0 \cdot 7(0 \cdot 4-1 \cdot 0) \\
1 \cdot 5(1 \cdot 0-2 \cdot 0) \\
2 \cdot 0(1 \cdot 4-2 \cdot 7) \\
2 \cdot 4(1 \cdot 7-3 \cdot 1) \\
3 \cdot 1(2 \cdot 2-3 \cdot 9)\end{array}$ \\
\hline Total & $\begin{array}{l}12 \\
24 \\
36 \\
48 \\
60\end{array}$ & $\begin{array}{l}0 \cdot 8(0 \cdot 4-1 \cdot 3) \\
1 \cdot 8(1 \cdot 0-2 \cdot 6) \\
2 \cdot 5(1 \cdot 5-3 \cdot 5) \\
3 \cdot 9(2 \cdot 5-5 \cdot 3) \\
5 \cdot 1(3 \cdot 3-6 \cdot 8)\end{array}$ & $\begin{array}{l}0 \cdot 9(0 \cdot 6-1 \cdot 3) \\
1 \cdot 6(1 \cdot 1-2 \cdot 2) \\
2 \cdot 2(1 \cdot 5-2 \cdot 9) \\
2 \cdot 7(1 \cdot 9-3 \cdot 5) \\
4 \cdot 8(3 \cdot 5-6 \cdot 2)\end{array}$ & $\begin{array}{l}1 \cdot 2(0 \cdot 8-1 \cdot 6) \\
2 \cdot 8(2 \cdot 1-3 \cdot 5) \\
4 \cdot 5(3 \cdot 5-5 \cdot 5) \\
4 \cdot 5(3 \cdot 5-5 \cdot 5) \\
*\end{array}$ & $\begin{array}{l}1 \cdot 2(0 \cdot 8-1 \cdot 6) \\
2 \cdot 7(2 \cdot 0-3 \cdot 4) \\
3 \cdot 9(3 \cdot 0-4 \cdot 7) \\
4 \cdot 5(3 \cdot 5-5 \cdot 5) \\
5 \cdot 8(4 \cdot 6-7 \cdot 0)\end{array}$ \\
\hline $\begin{array}{l}\text { Total No of fittings } \\
\text { Months observed }\end{array}$ & & $\begin{array}{r}2063 \\
44726\end{array}$ & $\begin{array}{r}3963 \\
71390\end{array}$ & $\begin{array}{r}3833 \\
65719\end{array}$ & $\begin{array}{r}3490 \\
83515\end{array}$ \\
\hline
\end{tabular}

*Insufficient data, fewer than 100 women remaining in the ordinal month described. 
just those cases in which infection was firmly diagnosed. This ignored the doctors' handwritten notes and relied exclusively on the marking of the infection box on the follow up form. Table II shows tnat even when the suspicion of infection was restricted to such cases no significant differences could be found between devices.

But there are weaknesses in life table analysis when comparing the experience of a large number of women each possessing a variety of characteristics. If a particular intrauterine device is fitted more often among women showing specific characteristics (such as age, parity, social class) then a comparison between devices may be unduly biased and an important event such as infection may be being hidden. Thus there may still be differences between devices when specific characteristics relating to the clinic and to the users, taken either singly or in combination, are examined. Particular sources of potential bias are possible differences in clinic practices, changes in the pattern

TABLE II-Life table: gross cumulative rates of infection reported per 100 women in those with a firm diagnosis and whose intrauterine device was removed. Values in parentheses are $95 \%$ confidence limits

\begin{tabular}{ccccc}
\hline Months of use & Lippes loop 2D & Lippes loop 3C & Gravigard & Dalkon shield \\
\hline 12 & $0 \cdot 3(0 \cdot 1-0 \cdot 6)$ & $0 \cdot 5(0 \cdot 2-0 \cdot 7)$ & $0 \cdot 4(0 \cdot 2-0 \cdot 6)$ & $0 \cdot 4(0 \cdot 2-0 \cdot 6)$ \\
24 & $0 \cdot 8(0 \cdot 4-1 \cdot 4)$ & $0 \cdot 7(0 \cdot 4-1 \cdot 1)$ & $1 \cdot 0(0 \cdot 6-1 \cdot 5)$ & $0 \cdot 8(0 \cdot 4-1 \cdot 1)$ \\
36 & $0 \cdot 9(0 \cdot 4-1 \cdot 5)$ & $0 \cdot 9(0 \cdot 5-1 \cdot 3)$ & $2 \cdot 2(1 \cdot 4-3 \cdot 0)$ & $1 \cdot 0(0 \cdot 6-1 \cdot 4)$ \\
48 & $1 \cdot 5(0 \cdot 7-2 \cdot 3)$ & $0 \cdot 9(0 \cdot 5-1 \cdot 3)$ & $2 \cdot 2(1 \cdot 4-3 \cdot 0)$ & $1 \cdot 2(0 \cdot 7-1 \cdot 8)$ \\
60 & $2 \cdot 1(1 \cdot 0-3 \cdot 2)$ & $1 \cdot 5(0 \cdot 9-2 \cdot 2)$ & $*$ & $1 \cdot 4(0 \cdot 8-2 \cdot 0)$ \\
\hline $\begin{array}{r}\text { Total No of } \\
\text { fittings }\end{array}$ & 2063 & 3963 & 3833 & 3490 \\
Months observed & 46291 & 73843 & 69359 & 87574
\end{tabular}

* Insufficient data, fewer than 100 women remaining in the ordinal month described. The months of observation are higher in table I owing to the inclusion of cases with
suspected infection but where no firm report was made and the device was not removed. of fittings during the selected time, and possible distinctive characteristics of women wearing specific intrauterine devices. We therefore analysed the data further, using multivariate techniques, to try to identify any such bias.

So that the information on each user was included only once we confined the analysis to first fittings only, which yielded data on 11439 women. For the purpose of examining infection rates all cases in which the outcome was not known-that is, were lost to follow up-were not used. This reduced the number of cases to 7794 , providing an equivalent annual loss to follow up rate of approximately $8.7 \%$ over the seven years.

\section{DIFFERENCES IN CLINIC PRACTICES}

Fittings of the four devices over 1971-5 to parous women were made in 17 participating clinics. The pattern of fittings for each device varied considerably (table III). In 1971 all the participating clinics fitted the Dalkon shield in $10 \%$ or more of their fittings, two clinics fitting the Dalkon shield exclusively during that year. During the period as a whole, however, the proportion of clinics not fitting the Dalkon shield rose to $62.5 \%$. The two years 1973 and 1974 had the highest proportion of clinics using all four devices and also had the highest proportion of clinics with $10 \%$ or more fittings with the Dalkon shield. The marketing of another intrauterine device, the Gravigard, in the early 1970s and North American publicity surrounding the Dalkon shield clearly affected the fittings of the Dalkon shield during the later period.

The infection rates by clinic varied from zero (no case of infection reported) to 25.97 per 1000 fittings. The estimates of infection rates by clinic for all intrauterine devices taken together were unstable with low event rates and thus comparatively small subsamples. Some differences between clinics were identified but when analysed

TABLE III-Fitting characteristics of 17 participating clinics by year (11 439 cases)

\begin{tabular}{|c|c|c|c|c|c|c|c|}
\hline Year & Base & $\begin{array}{c}\text { Clinics } \\
\text { not fitting } \\
\text { Dalkon shield }\end{array}$ & $\begin{array}{c}\text { Clinics } \\
\text { only fitting } \\
\text { Dalkon shield }\end{array}$ & $\begin{array}{l}\text { Clinics fitting } \\
\text { Dalkon shield and } \\
\text { one other device }\end{array}$ & $\begin{array}{l}\text { Clinics fitting } \\
\text { Dalkon shield and } \\
\text { two other devices }\end{array}$ & $\begin{array}{l}\text { Clinics fitting } \\
\text { all devices }\end{array}$ & $\begin{array}{l}\text { Clinics with } 10 \% \\
\text { or more fittings } \\
\text { with Dalkon shield }\end{array}$ \\
\hline $\begin{array}{l}1971 \\
1972 \\
1973 \\
1974 \\
1975\end{array}$ & $\begin{array}{r}6 \\
16 \\
16 \\
16 \\
16\end{array}$ & $\begin{array}{r}2 \\
2 \\
3 \\
10\end{array}$ & 2 & $\begin{array}{l}1 \\
4 \\
4 \\
4 \\
1\end{array}$ & $\begin{array}{l}2 \\
7 \\
2 \\
1 \\
3\end{array}$ & $\begin{array}{l}1 \\
3 \\
8 \\
8 \\
2\end{array}$ & $\begin{array}{r}6 \\
9 \\
10 \\
11 \\
3\end{array}$ \\
\hline Total & 17 & 1 & & 1 & 3 & 12 & 3 \\
\hline
\end{tabular}

In 1974 one clinic left the study and another clinic entered.

TABLE IV-Infection rates (per 1000 cases) according to device and year of fitting (7794 cases)

\begin{tabular}{|c|c|c|c|c|c|c|}
\hline Year & $\begin{array}{l}\text { Lippes } \\
\text { loop 2D }\end{array}$ & $\begin{array}{l}\text { Lippes } \\
\text { loop 3C }\end{array}$ & Gravigard & $\begin{array}{c}\text { Dalkon } \\
\text { shield }\end{array}$ & $\underset{\text { devices }}{\text { All }}$ & $\begin{array}{c}\text { No of } \\
\text { women }\end{array}$ \\
\hline $\begin{array}{l}1971 \\
1972 \\
1973 \\
1974 \\
1975\end{array}$ & $\begin{array}{r}7 \cdot 3 \\
7 \cdot 2 \\
4 \cdot 7 \\
18 \cdot 8\end{array}$ & $\begin{array}{r}6.5 \\
13.9 \\
4.4 \\
13.1\end{array}$ & $\begin{array}{r}12.7 \\
5.9 \\
11 \cdot 1 \\
10.1\end{array}$ & $\begin{array}{r}13.6 \\
13.5 \\
9.8 \\
10.8 \\
3.7\end{array}$ & $\begin{array}{r}11 \cdot 3 \\
10.4 \\
9 \cdot 6 \\
8.4 \\
11.5\end{array}$ & $\begin{array}{r}620 \\
1643 \\
1768 \\
1670 \\
2093\end{array}$ \\
\hline Total & $9 \cdot 7$ & $9 \cdot 9$ & $9 \cdot 7$ & $11 \cdot 1$ & $10 \cdot 1$ & 7794 \\
\hline $95 \%$ confidence limits & $4 \cdot 0-15 \cdot 4$ & $5 \cdot 7-14 \cdot 1$ & $5 \cdot 7-13 \cdot 6$ & $6 \cdot 7-15 \cdot 6$ & & \\
\hline No of cases & 1136 & 2122 & 2379 & 2157 & 7794 & \\
\hline
\end{tabular}

in a multiple regression analysis, in which the clinic was included as one of a number of possible causal variables, no significant difference existed.

\section{DIFFERENCES OVER TIME}

The infection rates by the year of fitting and the intrauterine device fitted are given in table IV. There was no significant difference in these infection rates by year. Even the difference of 3.09 per 1000 in the infection rates between 1974 and 1975 was not significant $(p=0.35)$ supporting the null hypothesis of no difference in the infection rates. Table IV also shows the infection rates for the four intrauterine

TABLE V-Differences in infection rates (per 1000 women) according to social class

\begin{tabular}{|c|c|c|c|c|c|c|c|}
\hline & Lippes loop 2D & Lippes loop 3C & Gravigard & Dalkon shield & Base & Infection rate per 1000 & Significance level against class $\mathrm{V}(\mathrm{p})$ \\
\hline $\begin{array}{l}\text { Class I } \\
\text { Class II } \\
\text { Class IIIN } \\
\text { Class IIIM } \\
\text { Class IV } \\
\text { Class V } \\
\text { Not employed }\end{array}$ & $\begin{array}{r}9.9 \\
10.5 \\
16.7 \\
24.4\end{array}$ & $\begin{array}{r}15 \cdot 5 \\
2 \cdot 5 \\
4 \cdot 2 \\
13 \cdot 5 \\
\\
19 \cdot 2 \\
38 \cdot 5\end{array}$ & $\begin{array}{r}6 \cdot 4 \\
2 \cdot 1 \\
11 \cdot 7 \\
12 \cdot 5 \\
4 \cdot 4 \\
34 \cdot 1\end{array}$ & $\begin{array}{r}19 \cdot 5 \\
15 \cdot 2 \\
11 \cdot 4 \\
11 \cdot 0 \\
8 \cdot 3 \\
35 \cdot 7\end{array}$ & $\begin{array}{r}440 \\
1385 \\
807 \\
2962 \\
708 \\
353 \\
90\end{array}$ & $\begin{array}{r}6 \cdot 8 \\
7 \cdot 2 \\
8 \cdot 7 \\
12 \cdot 2 \\
7 \cdot 1 \\
19 \cdot 8 \\
22 \cdot 2\end{array}$ & $\begin{array}{l}0.10 \\
0.03 \\
0 \cdot 11 \\
0.23 \\
0.06 \\
0.09\end{array}$ \\
\hline Total & $9 \cdot 8$ & $9 \cdot 7$ & $9 \cdot 5$ & $12 \cdot 7$ & & $10 \cdot 4$ & \\
\hline No of cases & 1021 & 1965 & 2109 & 1650 & 6745 & & \\
\hline
\end{tabular}


devices. The largest difference, of 1.4 per 1000 between the Dalkon shield and the Gravigard, was not significant $(p=0.64)$.

In looking at the interaction of year and device the only significant difference we found in infection rates between any year and device combination was between the Lippes loop 3C in 1974 and the Lippes loop 2D in 1975 at the $5.2 \%$ significance level. The infection rates associated with the Dalkon shield fitted in any of the five years were no different from those in any other year-device combination. same variables as the regression analysis. No intrauterine device variable was important. The canonical correlation coefficient was low but significant at the $0 \cdot 1 \%$ level of significance. The misclassification table indicated the effect of a significant but low canonical correlation coefficient, in that the proportion of cases which were correctly grouped retrospectively by the discriminant function was only $64.94 \%$. The conclusion of the discriminant analysis was to support the regression results presented.

\section{DIFFERENCES DUE TO THE USER}

The characteristics of the user showed no differences in relation to the reporting of infection except for the Registrar General's classification of social class. The infection rates according to social class and type of device are given in table $\mathrm{V}$. The difference at the $5 \%$ significance level in the infection rates, by social class for all devices together, was between social classes II and V, but this was the only consistent significant difference found. Some differences between specific class and device combinations did exist but followed no additional consistent pattern.

There was weak evidence $(p=0 \cdot 14)$ to suggest that the infection rate differed between users whose previous pregnancy had resulted in a live birth and those whose previous pregnancy had resulted in an abortion (spontaneous or induced). While there were limited differences between users with different characteristics, these differences were not related to the type of device being worn.

\section{MULTIVARIATE ANALYSES}

So far the effects of the four intrauterine devices in relation to selected variables have been presented with these variables in isolation from each other. An important consideration is the potential interaction of several variables leading to a report of infection. Two types of multivariate analysis were used to assess this, regression analysis and discriminant analysis.

In the regression analysis the dependent variable was a one-zero variable, taking the value one if the event was a report of infection, zero otherwise. The independent variables (regressors) were the complete set of information for the first fitting of a device in the study, including the characteristics of both the woman and clinic concerned. The categorical variables were partitioned into the appropriate number of dummy variables omitting the most common case to avoid colinearity with the constant term in the regression. When all clinics were taken together 27 variables were thus available for the regression analysis.

The most appropriate regression model gave a base infection rate estimated as 12.9 per 1000 . When all the devices were taken together the representative woman used the device for 24.3 months and had an infection rate of 8.5 per 1000 . The regression analysis permitted us to detect differences in infection rates according to the characteristics of the intrauterine device, the clinic, and the wearer. The differences discovered were in the months of use (each additional month reduced the infection rate by 0.2 per 1000 women), the year of use (being fitted in the earliest year raised the infection rate by $19 \cdot 1$ per 1000 ), the experience of abortion in the previous pregnancy (which increased the rate by 15.7 per 1000), and having a partner whose occupation was classified in social class $\mathrm{V}$ (which increased the rate by 11.8 per 1000 ). In the extremely adverse position, where all of these characteristics of regression were held by the same user, the infection rate was on average 55.1 per 1000 , which indicated that about 1 in 18 of such women would be reported as having infection. The regression analysis indicated that the data do support the identification of some characteristics that determine infection but that these were unrelated to the model of intrauterine device being worn.

Given all available information on the woman and clinic, there was no significant effect on the infection rate of fitting a Dalkon shield rather than a Gravigard, of fitting a Lippes loop 3C rather than a Gravigard, or of fitting a Lippes loop 2D rather than a Gravigard. All three coefficients were not significantly different from zero, with small values of the $t$ statistic. In any event the estimated difference in the infection rates between devices was only about 2 or 3 per 1000 . This indicated that there was no important difference in infection rates among the four devices assessed.

We also performed a discriminant analysis using the technique of minimising Wilk's $\lambda$. A seven variate optimal solution yielded the

\section{Discussion}

When interpreting the data provided in the tables several points should be borne in mind. Firstly, doctors may record pelvic infection in terms of its symptoms and signs on the follow up form rather than make a firm diagnosis of infection. The rates in table II may thus be underestimates. There is, however, no reason to suppose that this bias was any different among the four devices being compared. Secondly, undue weight should not be placed on the difference between treatment with removal of the intrauterine device and treatment without removal as an indication of differences in the severity of the infection. Thirdly, where treatment without removal of the intrauterine device takes place, the period of use was calculated from the date of fitting to the month in which treatment started. Where the device was subsequently removed the event was classified as a removal and the months of use calculated to the date of removal.

Tables I and II and their supporting tables indicate that there is little or no difference between the four devices studied in relation to each other and over time. In short, the Dalkon shield appears to be no better or worse in relation to reports of infection than any of the intrauterine devices that were commonly fitted from 1971 to 1975 with follow up being maintained until 1978. This lack of a distinctive relation of the Dalkon shield to infection applies both when the doctor specifically records pelvic infection or and when additional notes are included.

An examination of the variables associated with the clinic, the timing of fitting, and the wearer, suggests that any observed differences in reported infection rates are due to variables other than the type of intrauterine device fitted. No specific model was identified as being related to infection at a significantly higher rate than the other three examined. Claims that the Dalkon shield has unique disadvantages in relation to infection among intrauterine device users are not supported by this study.

We thank Professor Geoffrey Rose and Ms Margaret Booth of the Department of Epidemiology, London School of Hygiene and Tropical Medicine, and Professor Edward Kass of the Department of Medicine, Harvard Medical School, for their critical assessment of early drafts of this paper. We also wish to thank the medical teams in the UK intrauterine device research network and the thousands of users who have provided the information on which this study is based. Funding for the original data collection was provided by the Pathfinder Fund, USA, the Medical Research Council, UK, and the Department of Health and Social Security, UK. A grant was also received from A H Robins Ltd, USA, for the subsequent more detailed analysis.

\section{References}

${ }^{1}$ Lee NC, Rubin GL, Ory HW, Burkman RT. Type of intrauterine device and the risk of pelvic inflammatory disease. Obstet Gynecol $1983 ; 62: 1-6$

${ }^{2}$ Edelman DA, Berger GS, Keith L. The use of IUDs and their relationship to pelvic inflammatory disease: a review of epidemiologic and clinical studies. Current Problems in Obstetrics and Gynecology 1982;6: 1-62.

${ }^{3}$ Tietze C, Lewit S. Recommended procedures for the statistical evaluation of intrauterine contraception. Stud Fam Plann 1973;4:35-42.

(Accepted 1 March 1984) 